\title{
Response analysis of curve beam bridge under high earthquake intensity
}

\author{
Zhiqiang Chen ${ }^{1}$, Rui $\mathrm{Li}^{*}{ }^{*}$ Jin Zhao ${ }^{2}$ Zhenyu Xiu ${ }^{3}$ \\ 1 Yunnan Highway Science and Technology Research Institute, KunMing, \\ Yunnan,China; \\ 2 Henan Communications Planning Survey\&Design Institute CO.LTD, \\ Zhengzhou, Henan,China; \\ 3.College of Civil Engineering and Mechanics, Kunming University of \\ Science and Technology,KunMing,YunNan,China \\ *liruiking@163.com;447119104@qq.com
}

\begin{abstract}
Beam bridge is the main bridge of highway construction. Because of the limitations of the terrain, the most of mountain bridges are in the curves, so the seismic response of the bridge is relatively special. This paper is based on the study of response of the typical bridge on curve which are under high intensity earthquake action. Based on the study, this paper summarizes seismic response characteristics of these bridges, which can be referenced for the seismic design of similar bridges.
\end{abstract}

Keywords: bend; girder bridge; earthquake response; high earthquake intensity

\section{Introduction}

In recent years, in order to promote economic development in the western mountainous area, our country strengthen the investment of highway construction in the western regions.Because the bridge Plays a decisive role in the construction of a lifeline, so we need to strengthen the attention of bridge construction.

Because of the terrain and landform conditions, Mountain roads in our country have plenty of bends, steep slope, skew and high pier. Most of these mountain bridges are simply supported beam bridge which have 20 to 50 meters span or continuous beam bridges having 2 to 7 span every unit ${ }^{[1]}$.

When the bridge is located in the curve, the seismic response, especially the response in high intensity earthquake has its own characteristics which is that the spatial effect is particularly prominent.Therefore the plane calculation of the pier according to spectrum method in the specification is too simple and unreasonable. Without considering the spatial effect, this calculation method does not consider a lot of problems, which leads to the great difference between the calculation results 
and the real Spatial Seismic response. However mountainous bridge are most in the curve, and many are located in high earthquake intensity regions.so analysis and research on the seismic response of bridges and the proposed seismic measures based on these studies is very necessary.

\section{Damage of beam bridge in the earthquake}

Under the action of earthquake, the damage forms of the upper structure can be classified into three types: self injury, displacement damage and collision damage. The upper structure has large rigidity and good structural integrity, so its damage probability is teeny. Most of the damage is caused by displacement and collision. Because of the stress of the bridge deck system is not balanced,Curved bridge has the trend to reverse under the action of earthquakes, which leads to the lateral torsional coupling effect and the separation between the bridge superstructure and the support part, and then causes falling beams or superstructure damage ${ }^{[12]}$. The expansion joint is the weak point of the upper structure. Although it can solve the expected displacement generated by seismic action, the change of displacement of adjacent beams and displacement between beam body and abutment will cause collisions. All of these factors may ultimately lead to falling girder.

The forms of damage of bearing are mainly as follows: the support displacement, anchor bolt pull out, cut off, the support, the movable support structural damage ${ }^{[7]}$.

The damage of bearing is common in the earthquake. A stable support structure connection is fundamental to the stability of entire structure. The bridge dilapidation caused by the damage of the bridge connecting damage is not unusual. Bearing damage is caused by the bridge structure's non moving in the same direction, so that there could be unbearable relative displacement between the upper and the lower part of the supporting structure which leads to the failure. The reasons for this situation is that bearing design does not fully consider the earthquake and the selection of support form is improper and the supporting is insufficient.

Substructure failure include the failure of pier, abutment and foundation. These damage cause that bridge lose the capacity of bearing vertical load. So the failure of substructure is usually the direct cause of the bridge collapse.

\section{Finite element modelling of bridge structure}

In this paper, in the finite element modeling of the bridge, according to the component attribute the choices of different element types are simulated according to the different component attribute: the upper beam body structure and the lower structure of bridge pier is simulated by beam element, and expansion joints is simulated by gap element. Figure 1 shows the schematic diagram of gap element. 


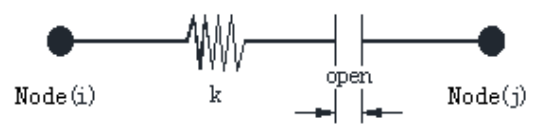

Fig 1: Schematic diagram of gap element

The relationship between gap element force and deformation can be described as follow:

$$
f=\left\{\begin{array}{cc}
k(d+\text { open }) & d+\text { open }<0 \\
0 & d+\text { open } \geq 0
\end{array}\right.
$$

In the formula:k-During the spring stiffness;d-Spring deformation;open-The initial gap.

When the absolute value of the relative displacement between two nodes is more than the initial gap within the unit, the freedom in this direction takes effect, and when use only the axial direction spring, it becomes compression unit ${ }^{[13]}$. This is Gap element .As shown in Figure 2, spring deformation is greater than the initial gap.So the stress increases rapidly with the deformation increase in accordance with the spring stiffness as the curvature.The joint collision reaction is usually simulated by using the gap element.

The clearance spring stiffness must be determined first in the modeling. In this paper, impact stiffness takes the axial rigidity of the beam ${ }^{[9]}$.

Support is simulated through a linear connection element. The vertical stiffness of the rubber bearings and the horizontal stiffness is selected according to the specification $^{[12,13]}$.

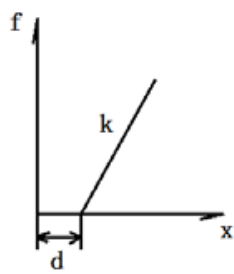

Fig 2: Gap element

\section{Engineering examples and modeling}

Using a secondary road in Yunnan which is a $8 \times 20$ metre structure of simply supported beam bridge whose deck is continuous prestressed $\mathrm{T}$ beam bridge.The bridge is located on the $\mathrm{R}=90.797 \mathrm{~m}$ radius of circular curve and the girder is formed with $5 \mathrm{~T}$ beam. The lower part of the structure is composed by variable cross-section hollow thin-walled pier and pile foundation:1\# 7\# pier were: $14 \mathrm{~m}$, $33 \mathrm{~m}, 41 \mathrm{~m}, 39 \mathrm{~m}, 31 \mathrm{~m}, 16 \mathrm{~m}, 10 \mathrm{~m}$ and using the gravity abutment. Full bridge is two joint.Expansion joint is arranged between the two abutment and pier corresponding 4\# .Deck use 80 type expansion joint.Specifications of rubber bearing is $\Phi 250 \times 44.5 \mathrm{~mm}$. The seismic intensity is 9 degrees.

The calculation model is shown in Figure 3 and pier beam connection model is shown in Figure 4 . The $\mathrm{X}$ direction of the global coordinate is the direction of a 
line with the starting and ending of the bridge.Y direction and $\mathrm{X}$ direction is vertical with each other.in the model, the effect of pile soil interaction between the foundation and the pier is not considered.And Between the foundation is consolidated with the pier.

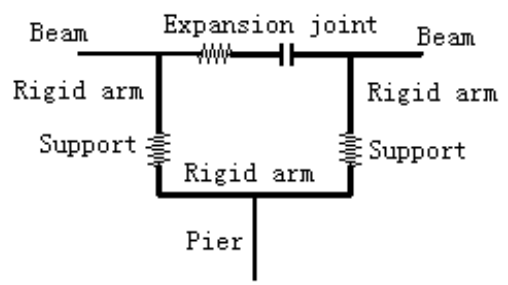

Fig 3: The whole bridge finite element model model

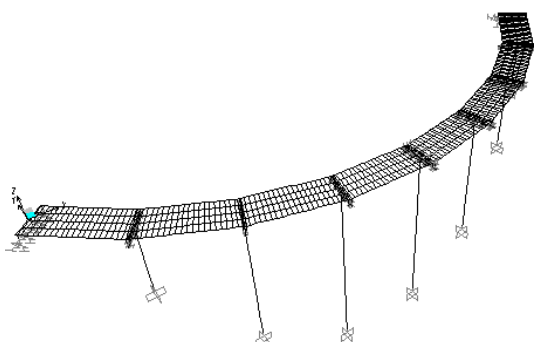

Fig 4: The local finite element

\section{Response analysis of curve beam bridge in the earthquake}

Considering the site condition, the paper selects the typical earthquake records of El-Centro earthquake wave to analyse the seismic response.This paper takes the the beginning $20 \mathrm{~s}$ of the seismic wave and the interval is $0.02 \mathrm{~s}$ and add the peak acceleration amplitude to $0.4 \mathrm{~g}$. Besides considering the seismic wave's bi-directional input,the paper uses the consistent excitation input. Two kinds of seismic wave form of combination are as follow: 1 . The line of start and finish direction takes $+30 \%$ vertical input; The vertical line of start and finish direction takes $+30 \%$ vertical input.

\subsection{Effects of bearing arrangement}

Through the original model (modeling according to the actual situation) and three comparison model (model one or two, three, have set up a fixed support) contrast calculation results, the paper analyzes the effects of bearing arrangement on the dynamic characteristic of a bridge on curve:

The model-0 (The original model) :The original bridge superstructure has two units. A expansion is arranged corresponding to the joint $4 \#$ bridge pier.The full bridge is not provided with a fixed bearing. Under expansion joints, there are sliding bearings. The rest of the pier are equipped with the laminated rubber bearings,Every bearing should be simulated according to the actual situation; Model-1: fixed support is arranged on the two ends of the abutment position.The continuous bridge deck bearings at rest are the laminated rubber bearings. Under expansion joints, there are sliding bearings.

Model-2:The fixed support is setted on the expansion joint which is located on pier which is adjacent to $4 \#$ expansion ( $3 \#$ and $5 \#$ pier).The laminated rubber bearings are used under the rest of the pier and sliding bearings are used in the abutment;

Model-3: the fixed seat is positioned in the middle of each bridge pier (2\# and 6\# pier). The laminated rubber bearings are used under the rest of the pier and sliding bearings are used in the abutment; 
The low order vibration type of bridges located on curve is mainly the translation in plane and the rotation of $\mathrm{Z}$ axis. While the lateral torsional coupling phenomena often occur in the high order mode ${ }^{[11]}$.

4.1.1 The influence of self vibration characteristics

The calculation results of self vibration period of four kinds of models of the first 20 vibration type is shown in Figure 5 . As you can see from Figure 5, bridges setted with fixed support have more short natural period of vibration compared to the original structure. Actually, the fixed support increases stiffness of the full bridge, and when the fixed support is positioned on the abutment, the increases of stiffness is particularly obvious.

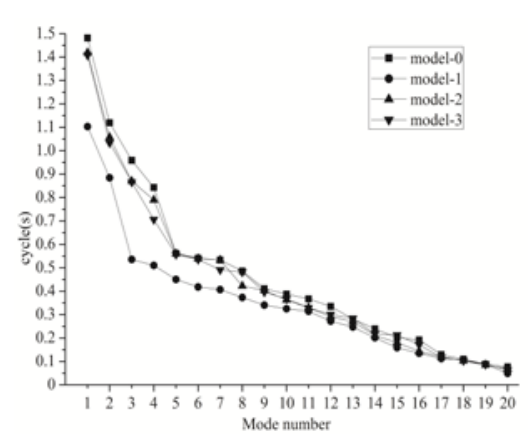

Fig 5:The effect of fixed bearing arrangement on vibration period

4.1.2 Effect on seismic response

The result of Calculation showed that: under the action of earthquake, the maximum bending moment of two associated values were appeared in the $3 \#, 6 \#$ location of pier. Therefore, this paper provides only the two piers of the bridge seismic response(see Table 1 to Table 4). As can be seen from the calculations, under the earthquake action in the two direction, radial direction (transverse) moment values were larger than the tangential (along the bridge to) moment. while for the straight bridge, earthquake direction bending moment is generally large than the bending moment ${ }^{[11]}$ perpendicular to the direction of the earthquake. The bottom radial bending moment and tangential moment of $3 \#$ pier in model-3 is larger than model-0.while the pier bottom radial bending moment of $3 \#$ pier in model-1and model-2 are smaller than model-0. And setted up a fixed support, bottom tangential bending moment of $6 \#$ pier are reduced. Thus, the location of fixed support has little effect on the distribution of earthquake response.

Table 1 Response of different models of pier No. 3 in X direction under the action of earthquake 


\begin{tabular}{ccccccc}
\hline & $\mathrm{M}_{\mathrm{R}}(\mathrm{KN} \cdot$ & $\mathrm{M}_{\mathrm{T}}(\mathrm{KN} \cdot$ & $\mathrm{Q}_{\mathrm{R}}(\mathrm{KN})$ & $\mathrm{Q}_{\mathrm{T}}(\mathrm{KN})$ & $\mathrm{D}_{\mathrm{T}}(\mathrm{cm})$ & $\mathrm{D}_{\mathrm{L}}(\mathrm{cm})$ \\
\hline Model-0 & 58659.4 & 13786.7 & 4798.2 & 2500.7 & 21.7 & 33.1 \\
Model-1 & 53560.2 & 11757.4 & 4751.4 & 3998.2 & 17.8 & 21.9 \\
Model-2 & 44689.3 & 13985.6 & 3975.2 & 2395.8 & 20.8 & 17.8 \\
& & & & & & \\
Model-3 & 69998.5 & 27986.1 & 5653.4 & 3012.4 & 17.5 & 29.5 \\
\hline
\end{tabular}

Table2 Response of different models of pier No. 3 in Y direction under the action of earthquake

\begin{tabular}{|c|c|c|c|c|c|c|}
\hline & $\mathrm{M}_{\mathrm{R}}(\mathrm{K}$ & $\mathrm{M}_{\mathrm{T}}(\mathrm{K}$ & $\mathrm{Q}_{\mathrm{R}}(\mathrm{KN}$ & $\mathrm{Q}_{\mathrm{T}}(\mathrm{KN}$ & $\mathrm{D}_{\mathrm{T}}(\mathrm{cm}$ & $\mathrm{D}_{\mathrm{L}}(\mathrm{cm})$ \\
\hline Model- & 17258. & 14857. & 2853.7 & 3352.4 & 8.5 & 12.0 \\
\hline Model- & 17315. & 13524. & 1975.3 & 2785.3 & 8.1 & 3.5 \\
\hline Model- & 17456. & 11872. & 2687.3 & 2105.9 & 8.8 & 8.5 \\
\hline Model- & 16459. & 11866. & 2207.8 & 1997.6 & 10.5 & 14.0 \\
\hline \multicolumn{7}{|c|}{$\begin{array}{c}\text { Table3 Response of different models of pier No. } 6 \text { in X direction under the action } \\
\text { of earthquake }\end{array}$} \\
\hline & $\mathrm{M}_{\mathrm{R}}(\mathrm{K}$ & $\mathrm{M}_{\mathrm{T}}(\mathrm{K}$ & $\mathrm{Q}_{\mathrm{R}}(\mathrm{K}$ & $\mathrm{Q}_{\mathrm{T}}(\mathrm{K}$ & $\mathrm{D}_{\mathrm{T}}(\mathrm{cm}$ & $\mathrm{D}_{\mathrm{L}}(\mathrm{cm}$ \\
\hline Model- & 57068. & 9986.2 & 6765.3 & 2400.0 & 20.8 & 21.7 \\
\hline Model- & 40155. & 6500.3 & 3515.5 & 1750.3 & 9.1 & 10.4 \\
\hline Model- & 42576. & 5742.5 & 6410.2 & 1577.0 & 22.3 & 12.8 \\
\hline Model- & 84973. & 17985. & 9505. & 3087.6 & 19.7 & 16.6 \\
\hline
\end{tabular}

Table4 Response of different models of pier No. 6 in Y direction under the action of earthquake

\begin{tabular}{ccccccc}
\hline & & & & & \\
& $\mathrm{M}_{\mathrm{R}}(\mathrm{K}$ & $\mathrm{M}_{\mathrm{T}}(\mathrm{K}$ & $\mathrm{Q}_{\mathrm{R}}(\mathrm{K}$ & $\mathrm{Q}_{\mathrm{T}}(\mathrm{K}$ & $\mathrm{D}_{\mathrm{T}}(\mathrm{cm}$ & $\mathrm{D}_{\mathrm{L}}(\mathrm{cm}$ \\
\hline Model- & 28575. & 6430.2 & 5905.2 & 1850.7 & 4.5 & 13.3 \\
Model- & 19972. & 5243.2 & 4457.1 & 1545.7 & 3.2 & 8.1 \\
Model- & 24967. & 3142.5 & 4212.3 & 8975.7 & 3.1 & 8.4 \\
Model- & 24975. & 7996.5 & 7500.0 & 2410.5 & 3.7 & 11.3 \\
\hline
\end{tabular}


From the calculation results can be seen:setting the fixed bearing on the piers which are adjacent to expansion joints or on the highest pier is beneficial to improving the overall bridge seismic performance. This result has a certain deviation with the conclusions based on straight bridge analysis in the past. The view of the past is that the fixed support should be placed in short pier ${ }^{[14]}$.

Because there are 5 pieces of upper structure girder beam, and bridges located in inside the curve, in order to analyze the collision curves from the medial to lateral,so longitudinal beam are connected with gap element and expansion joints are in a total of 5 gap element, which is numbered from left to the right of bridge deck. When researching on collision response, if only inputting seismic wave of $X$ direction, the calculation results are shown in Table 5.

Due to the translation of curve beam bridge in the plane in the two directions, and if the height of adjacent pier are quit different, the self vibration period will be different, so the expansion joints are easy to collide. So some measures should be adopted in the design to fills the buffer material with certain stiffness and damping in the main beam and effectively reduce the structural impact.Besides more attention should be paid to the outboard curve ${ }^{[11]}$.

4.2 Bridge deck continuous influence on seismic response of curved bridges For comparison, we remove the upper structure joints located on the 4\# bridge pier and Merge the upper structure into a unit, and compare the two coupling seismic response with the original ones and analyze the influence on the bridge part of the earthquake action.

4.2.1 The influence of self vibration characteristics

The calculation results of the natural vibration period of the first 20 mode in two cases are shown in Figure 6. As you can see from Figure 6, when the original upper structure is change from one to two link a united, all periods of vibration modes decrease, and the period of low order vibration type decreases more. Calculation showed that: $1 \sim 16$ modes mainly in XY plane movement, 17 order after torsion vibration mode.

4.2.2 Effect on seismic response

Because the length of the paper is confined, we do not list the concrete computation. Computing results, if the telescopic No. 4 pier above the seam is cancelled, seismic response shows the following trends:

1)Under the action of earthquake on $X$ direction, the bottom moment and shear force of the pier except that tangential bending moment of $3 \#$ pier increased, are reduced, and the tangential bending moment and radial shear of $6 \#$ pier are reduced most. The displacement of the top pier are all increased except the displacement along the bridge of $3 \#$ pier and the transvorse displacement of 2\# and $3 \#$,among which the increase of along the bridge displacement of $5 \#$ pier is the largest.

2)In the $Y$ direction, under the action of earthquake, in addition to radial bending moment and pier radial shear of $3 \#$ pier and the bending moment $5 \#$ pier, the rest are decreased, among which the decreases of the radial bending moment of $3 \#$ pier and the radial shear of $6 \#$ pier are the largest. The displacements of top pier along the bridge are reduced .And in addition to the transverse displacement of 2\#, 3\# and $4 \#$ pier, the rest are reduced. 
From the above analysis results, the stiffness of the whole structure increases when upper structure adopts a combined form .On the whole, most of pier forces decrease.

\subsection{Expansion joint location effect on dynamic characteristics of curved bridge}

Considering the influence of different position of joint on bridge, we list three situations: the expansion joint is arranged on the 3\# pier; expansion joint is arranged on the $5 \#$ pier and the actual situation (the expansion joint is arranged on the $4 \#$ bridge pier).

The calculation results show that: the whole set of expansion joint position does not affect the natural period of the structure, but it greatly impact seismic response of two adjacent coupling structure. when expansion joint is setted on $3 \#$ pier, the natural vibration period of expansion joint of two adjacent link structure are close, and the internal force value is large and the number of collisions is the least. But the internal force is large under the action of earthquake; when the expansion joint is setted on 5\# pier, the self vibration period expansion of two adjacent units between two joints is quite different compared with other two kinds of situations. In this situation, the forceis more small than the other two kinds of situations, but the collision is more. The analysis also found that, the beam body collision is beneficial to reduce seismic response, which is in accord with "fuse" consistent theory about collision ${ }^{[9,15]}$. Collision can consume the earthquake energy, However, suiTable structure shall be provided to protect the bridge structure from collision damage.

\section{The conclusions and suggestions}

Aiming at the bridge on curve of spatial earthquake response analysis, the paper compares the calculating results and conclusions are as follows:

1) Mode of vibration of curved bridge is mainly translational and rotational in plane.Due to deviations of the upper structure from the center of gravity, the expansion joint of curved bridges are vulnerable to the uneven impact, so more attention should be paid to seismic design of outboard curve;

2) Setting a fixed support can increase the stiffness of the whole bridge,so changing "floating system"in the actual project is considerable in the design. And the fixed support setting can reduce the stress in pier, and it also improve the seismic performance of the whole bridge;

3) Without expansion joint in the upper structure, can improve the overall bridge stiffness and strength is improved. And the influence on the bridge direction is more significant .Therefore, when Conditions permit , the continuous type is more reasonable for upper structure;

4) When two adjacent link structure period is close, the probability of collision can be greatly reduced,.But the same trend of movement and speed will increase the seismic response of the structure. The results of this paper is that the collision plays a role of energy consumption, so it can reduce the earthquake action.Therefore joint filled with cushion material which has certain stiffness and 
damping can protect the upper structure from collision damage;

\section{References}

[1] Rui Li,Liaoyuan Ye,Zhongheng Yang.The selection and design of bridge high pier in high intensity seismic region[J].Journal of Kunming University of Science and Technology ( Science and Technology Edition) ,2008,33(1):52 55 .

[2] Rui Li,Liaoyuan Ye, Yitang Zhou.Analysis of mountain hollow thin-walled high pier structure and mechanics[J].Highway,2007(11):46 50 .

[3] Rui Li,Jing Zhao.Seismic concept design of Interchange Ramp Bridge District[J].Highway traffic science and technology (Application and Technology Edition ) ,2012(6):225-228.

[4] Haijun Yin,Lei Xu,YueKui Shen.To investigate the mechanism of bridge d amage in Wenchuan earthquake[J].Journal of Xi'an University Of Architect ure And Technology,2008,40(5):672 677.

[5] Tao Lei,Bixiong Li,Pengjie Cao.Wenchuan earthquake near fault near the bridge damage analysis[J].Journal of Chongqing Jiaotong University(Natur al Science Edition),2010,29(3):358 362.

[6] DesRoches R, Delemont M. Seismic Retrofit of Simply Supported Bridges Using Shape Memory Alloys[J]. Engineer Structure 2002,(24):325 332.

[7] Maria Q Feng, Jae-Min Kim, Masanobu Shinozuka etal. Viscoelastic Dampers at Expansion Joints for Seismic Protection of Bridges[J]. Journal of Bridge Engineering, 2000,5(5):67 74.

[8] Yucheng Shi,Hongwei Cai,Huiping Xu.The uncertainty and its processing method for seismic response analysis[J].The Fifth National Conference on Earthquake Engineering,1998,166 171.

[9] Junwen Wang,Jianzhong Li,Lichu Fan.Bridge seismic collision effect and beam falling prevention measures research status[J].Highway traffic scienc e and technology,2007(24):71 75.

[10] Minhong Zhang.Change and comparative study of highway bridge China seismic design codes[D]. Xi'an:Chang'an University,2010.

[11] Jing Zhao.Selection and the anti-seismic structure in high intensity earthquake Mountain Bridge[D].Kunming:Kunming University of Science and Technology,2012.

[12] Rui Li,Liaoyuan Ye,Zhiben Yang.Spatial earthquake response analysis of curve bridge[J]. Highway engineering, 2007(32):27 29.

[13] Huxiang Yang,Hang Xu.Research and design of high intensity seismic bridge in mountain area[J].Highway,2009(8):246 250.

[14] Peijun Zhang. Analysis of seismic response of irregular girder bridge [D].Shanghai:Tongji University,2005. 